Scientific paper

\title{
Aggregates of Isotactic Poly(methacrylic acid) Chains in Aqueous CsCl Solutions: a Static and Dynamic Light Scattering Study
}

\author{
Katarina Hočevar, Simona Sitar and Ksenija Kogej* \\ Faculty of Chemistry and Chemical Technology, University of Ljubljana, Večna pot 113, P.O. Box 537, \\ SI-1001 Ljubljana, Slovenia \\ * Corresponding author: E-mail: ksenija.kogej@fkkt.uni-lj.si \\ Tel: $+(386-1)-479-8538$
}

Received: 06-03-2015

Dedicated to prof. Jože Koller on the occasion of his $70^{\text {th }}$ birthday.

\begin{abstract}
Properties of isotactic polymethacrylic acid, iPMA, chains were studied at $25^{\circ} \mathrm{C}$ in aqueous solutions at various $\mathrm{CsCl}$ concentrations, $c_{\mathrm{s}}(=0.05-0.20 \mathrm{M})$, in dependence on degree of neutralization of the polyion's carboxyl groups, $\alpha_{\mathrm{N}}$, using static, SLS, and dynamic light scattering, DLS, measurements. It was demonstrated that iPMA chains with $\alpha_{\mathrm{N}}$ somewhat above the solubility limit of iPMA in aqueous solutions (in the present case at $\alpha_{N} \approx 0.27$ ) are strongly aggregated. The size of the aggregates increases with increasing $c_{\mathrm{s}}$, whereas the shape parameter, $\rho$, is approximately constant ( $\rho \approx 0.6$ ), irrespective of $c_{\mathrm{s}}$. The low $\rho$ value suggests that the aggregates have characteristics of microgel particles with a dense core surrounded by a less dense corona. The diffusion of iPMA chains was investigated also at higher $\alpha_{\mathrm{N}}$, up to $\alpha_{N}=1$. The polyion slow mode arising from electrostatic interactions between charged chains was observed for $\alpha_{N}$ exceeding the value 0.27 even at the highest $c_{\mathrm{s}}(=0.20 \mathrm{M})$. The diffusion coefficients for the show mode were nearly independent of $\alpha_{\mathrm{N}}$ and $c_{\mathrm{s}}$ at the studied polymer concentration.
\end{abstract}

Keywords: isotactic poly(methacrylic acid), light scattering, hydrodynamic radius, shape parameter, aggregation, polyelectrolyte slow mode

\section{Introduction}

Intermolecular association and aggregate formation are important in nature and technology. Some examples from the biological field are formation of two- or threestranded polynucleotides, supramolecular assemblies in virus shells, gelation of polysaccharides, and some from the technological field are polymer-surfactant and polymer-polymer complexation systems that are often used as materials for pharmaceutical applications. ${ }^{1}$ Very stable inter-polymer complexes are formed when a cationic and an anionic polyelectrolyte are mixed in solution; this is a result of strong electrostatic attraction between the oppositely charged polyions and of the concomitant entropy in- crease due to the release of their counterions into the solution. Aggregates can also form between chains of the same polymer, if uncharged or weakly charged, very frequently through intermolecular H-bond formation and/or by the help of van der Waals forces and the hydrophobic effect. Hydrogen bonding is a major driving force for complexation of poly(carboxylic acids). ${ }^{2-5}$ Although a single H-bond can be rather weak (with an energy 2-167 $\mathrm{kJ} / \mathrm{mol}){ }^{6}{ }^{6}$ simultaneous formation of a large number of such bonds between two macromolecules (a cooperative phenomenon) may lead to very strong association.

In this contribution, we focus on intermolecular association between the isotactic poly(methacrylic acid), iPMA, chains in aqueous solutions. iPMA is a highly regu- 
lar form of poly(methacrylic acid), PMA, predominately composed of isotactic triads (i.e. sequences of two meso diads, denoted as $m m$ ). The other ordered isomer is the syndiotactic PMA, sPMA, made up of syndiotactic triads (the $r r$ sequences, with $r$ for the racemo diad), whereas the randomly substituted PMA is called the atactic or heterotactic PMA, aPMA, and contains, in addition to $\mathrm{mm}$ and $r r$, also the heterotactic, $r m$, triads. Solution properties, ${ }^{2-5,7-14}$ intermolecular association, ${ }^{4,5,13}$ and binding of species $^{5}$ all depend on polymer tacticity. For example, while sPMA and aPMA dissolve in water and show similar solution behavior, ${ }^{8,9}$ in part because aPMA is normally predominately syndiotactic, iPMA is insoluble in water unless the degree of neutralization of carboxylic acid groups, $\alpha_{\mathrm{N}}$, exceeds a value $\alpha_{\mathrm{N}} \approx 0.2 .^{8,9,14}$ Insolubility of $\mathrm{i}$ PMA originates from the ordered helical conformation of the chain, which is favorable for intermolecular association. ${ }^{3,5,13,14}$ It has been recently demonstrated that the regularity on the level of a single chain also leads to gelation of iPMA in concentrated solutions. ${ }^{13}$

iPMA and aPMA are both strongly associated in dilute solutions too if $\alpha_{\mathrm{N}}$ is low ( $\alpha_{\mathrm{N}}=0$ and $\sim 0.25$ for aPMA and iPMA, respectively). This was demonstrated by light scattering, LS, studies ${ }^{15,16}$ in aqueous solutions with added alkali chlorides. However, important differences in the association mechanism exist between the two stereoizomers. For example, the number of aPMA aggregates increases as a result of shearing the solution (a phenomenon known as negative thixotropy ${ }^{4,17}$ ), whereas the iPMA ones disintegrate due to shear stress and reform in solutions at rest. ${ }^{15}$ In equilibrium, the extent of aggregation is larger for iPMA than it is for aPMA. Besides, iPMA aggregates are observed at a non-zero $\alpha_{\mathrm{N}}$ value (somewhat above the solubility limit, which is at $\alpha_{\mathrm{N}} \approx 0.2$ ), whereas the aPMA ones exist in solution only close to $\alpha_{\mathrm{N}}=0$. In both cases, ${ }^{15,16}$ the aggregates have characteristics of microgel particles with a core-shell structure, but the iPMA ones have a denser core.

Beside the properties of the polymer chain, intermolecular association depends also on the solution conditions. In the case of charged polymers (iPMA at $\alpha_{\mathrm{N}} \approx 0.27$ is charged) in aqueous solutions, interactions are most frequently tuned by the addition of an inert low molecular weight salt. In our study, we have varied the concentration of $\mathrm{CsCl}$ in the concentration range from $0.05-0.20 \mathrm{M}$. Static, SLS, and dynamic light scattering, DLS, were used to determine the radius of gyration, $R_{\mathrm{g}}$, and the hydrodynamic radius, $R_{\mathrm{h}}$, of particles in iPMA solutions, from which the shape parameter, $\rho\left(=R_{\mathrm{g}} / R_{\mathrm{h}}\right)$, was evaluated. The value of $\rho$ is a convenient measure of the shape/architecture of particles and also of their eventual aggregated state in solution.

We have furthermore extended our LS investigations to studying diffusion of iPMA chains in solutions at higher $\alpha_{N}$ values (all up to $\alpha_{N}=1$ ) where inter-chain aggregates are expected to break and the dimensions of individual
iPMA chains should increase due to intramolecular repulsion between the charged carboxyl groups. Fully charged polymer chains are stiffer than the uncharged ones and their mutual interaction is strongly repulsive unless sufficient number of counterions (from the inert salt) is present in solution to screen these repulsions. Due to inter-chain repulsion, polyions move faster in solution than the corresponding neutral polymers of the same degree of polymerization; consequently, a higher value of the diffusion coefficient, $D$, is detected by DLS. ${ }^{21}$ Accordingly, this diffusion mode is often called the "fast mode". ${ }^{21}$ The result of inter-chain repulsion is yet another diffusive mode, so called "slow mode" that exhibits much lower $D$ values in comparison to the fast mode. This mode originates from the formation of so called "polyion domains" in solution, within which the motion of polyion chains is correlated, i.e. affected by other chains. The attributed "apparent size" of these domains exceeds the size of individual chains and can reach values around $100 \mathrm{~nm} .{ }^{21}$ Polyion domains are metastable but long lasting structures in solutions of polyelectrolytes. Certain physical measurements, one of them being DLS, are able to detect these "domains" as "particles" with their own value of $D$, and, through the Stoke-Einstein equation, the value of $R_{\mathrm{h}}$. The slow mode is detected at high polyion concentrations, in the case of strongly charged chains, at low concentrations of the added simple salt (or in salt-free systems) and at high molecular weights of polyelectrolytes. It was demonstrated that the nature of the added salt is important as well. ${ }^{16}$ In the case of an anionic polyelectrolyte like PMA, the decisive is the added cation. Thus, it was shown that $\mathrm{Li}^{+}$and $\mathrm{Na}^{+}$ions better support interchain aggregation than do $\mathrm{Cs}^{+}$ ones. ${ }^{16}$ That study ${ }^{16}$ was performed at a single salt concentration, i.e. in $0.1 \mathrm{M} \mathrm{CsCl}, \mathrm{NaCl}$, and $\mathrm{LiCl}$. In the present investigation we want to further explore the effect of decreasing/increasing the concentration of $\mathrm{CsCl}, c_{\mathrm{S}}$, on intermolecular association and slow mode phenomenon in $\mathrm{i}$ PMA solutions.

\section{Experimental}

\section{1. Materials}

The starting iPMA was prepared by hydrolysis of the isotactic polymethylmethacrylate, iPMMA, as reported in the literature. ${ }^{13}$ Tacticity of iPMMA (93\% of isotactic, $3 \%$ of syndiotactic and $4 \%$ of atactic triads) was determined from the ${ }^{1} \mathrm{H}$ NMR spectrum in $\mathrm{CDCl}_{3}$. The weight average molecular weight, $M_{\mathrm{w}}(=32000 \mathrm{~g} / \mathrm{mol})$, and the polydispersity index, PDI $(=2.93)$, were obtained by size exclusion chromatography. ${ }^{15}$

Stock solutions were prepared by suspending dry iPMA powder in triple distilled water and then slowly adding a calculated amount of $1 \mathrm{M} \mathrm{CsOH}$ in order to dissolve the polymer. The solution was stirred for $\sim 24$ hours before further handling. The exact polymer concentration, 
$c_{\mathrm{p}}$, and $\alpha_{\mathrm{N}}$ value were determined by potentiometric titration with $\mathrm{HCl}$ and $\mathrm{NaOH} . \alpha_{\mathrm{N}}$ of the stock solution was 0.53 and $c_{\mathrm{p}}$ was $5.434 \mathrm{~g} / \mathrm{L}$. Higher $\alpha_{\mathrm{N}}$ values $\left(\alpha_{\mathrm{N}}>0.53\right)$ were reached by adding $1.027 \mathrm{M} \mathrm{CsOH}$ and lower ones $\left(\alpha_{\mathrm{N}}<0.53\right)$ by adding $1.0 \mathrm{M} \mathrm{HCl}$. At the end, $1 \mathrm{M} \mathrm{CsCl}$ was added to all stock solutions in order to achieve the desired $\mathrm{CsCl}$ concentration. In this way, 20 different samples were prepared with $\alpha_{\mathrm{N}}=0.27,0.40,0.53,0.75$ and 1.00, and with 4 different concentrations of $\mathrm{CsCl},\left(c_{\mathrm{s}}=0.05\right.$, $0.07,0.10$ and $0.20 \mathrm{M}$ ), for each $\alpha_{\mathrm{N}}$. The final concentration of iPMA for LS studies was in all cases set to $c_{\mathrm{p}}=2$ $\mathrm{g} / \mathrm{L}$. It has been shown previously ${ }^{16}$ that $D\left(R_{\mathrm{h}}\right)$ values of particles in iPMA solutions are affected by $c_{\mathrm{p}}$, but the shape parameter $\rho$ (i.e. the nature of particles) is independent of $c_{\mathrm{p}}$. Because the aim of the present investigation was to study the nature of iPMA aggregates in depencence on $c_{\mathrm{s}}$, a constant $c_{\mathrm{p}}$ value was employed.

\section{2. Light Scattering Measurements}

Light scattering measurements were performed with the 3D-DLS-SLS cross-correlation spectrometer from LS Instruments $\mathrm{GmbH}$ (Fribourg, Switzerland). As a light source the He-Ne laser with a wavelength $\lambda_{\mathrm{o}}=632.8 \mathrm{~nm}$ was used. All samples were filtered through hydrophilic $0.22 \mu \mathrm{m}$ Millex-HV filters directly into the cylindrical measuring cell and left standing for about one hour at room temperature. LS measurements were carried in the angular range from $30^{\circ}$ to $150^{\circ}$ with a step of $10^{\circ}$ after equilibrating the samples at $25^{\circ} \mathrm{C}$ for 30 minutes. Constant intensity of light scattered at $90^{\circ}$ was used as a criterion that the solution was properly equilibrated. 5 intensity correlation functions were collected at each angle and averaged. Each curve was analysed independently and compared with the averaged curve to ensure accuracy of the mathematical solution.

Detailed methodological aspects of DLS and SLS can be found elsewhere. ${ }^{18,19}$ Herein, correlation functions of the intensity of scattered light, $G_{2}(t)$, were recorded simultaneously with the integral time averaged intensities,

$I_{\theta} \equiv I_{\mathrm{q}}$, where $q\left(=\frac{4 \pi n_{0}}{\lambda_{0}} \sin \frac{\theta}{2}\right)$ is the scattering vector, $n_{\mathrm{o}}$

the refractive index of the medium, and $\theta$ the scattering angle. Intensities measured in counts of photons per second (cps) were normalized with respect to the Rayleigh ratio, $R$, of toluene thus converting the cps-units into the absolute intensity units given in $\mathrm{cm}^{-1}$.

The radius of gyration, $R_{\mathrm{g}}$, of particles, was determined from the form factor, $P(q)\left(=I_{\mathrm{q}} / I_{0}\right.$, where $I_{0}$ is the scattering intensity at $\theta(q)=0$ ), by using the following equations: ${ }^{22}$ (i) the Zimm function (Equation 1) which is valid when particle sizes fulfill the criterion $q R_{\mathrm{g}}<1$ :

$$
P(q)=\frac{1}{1+\frac{(q R g)^{2}}{3}}
$$

(ii) the Debye function (Equation 2) used for polymer chains with a Gaussian distribution of segments:

$$
P(q)=\frac{2}{\left(q R_{g}\right)^{4}}\left(\left(q R_{g}\right)^{2}-1+e^{-\left(q R_{g}\right)^{2}}\right)
$$

and (iii) the Debye-Bueche scattering function (Equation 3) which applies to a spherical distribution of points around the center of gravity (such as in gels, networks, cross-linked or branched polymers), which is more random than the Gaussian distribution:

$$
P(q)=\frac{1}{\left(1+\frac{(q R g)^{2}}{6}\right)^{2}}
$$

In order to determine $R_{\mathrm{h}}$, the measured $G_{2}(t)$ was converted into the correlation function of the scattered electric field, $g_{1}(t)$, by using the Siegert's relationship. For monodisperse particles, small in size compared to the wavelength of light as well as for hard spheres of any size, the $g_{1}(t)$ is related to the translational diffusion coefficient, $D$, of particles through

$$
\left|g_{1}(t)\right|=e^{-t / \tau}=e^{-\Gamma t}=e^{-D q^{2} t}
$$

where $\tau$ is the relaxation (or decay) time and $\Gamma\left(=\tau^{-1}=\right.$ $D q^{2}$ ) is the relaxation (decay) rate. The $R_{\mathrm{h}}$ of particles is then obtained from $D$ via the Stokes-Einstein equation

$$
R_{h}=\frac{k T}{6 \pi \eta_{0} D}
$$

where $k$ is the Boltzmann constant, $T$ the absolute temperature, and $\eta_{0}$ the solvent viscosity.

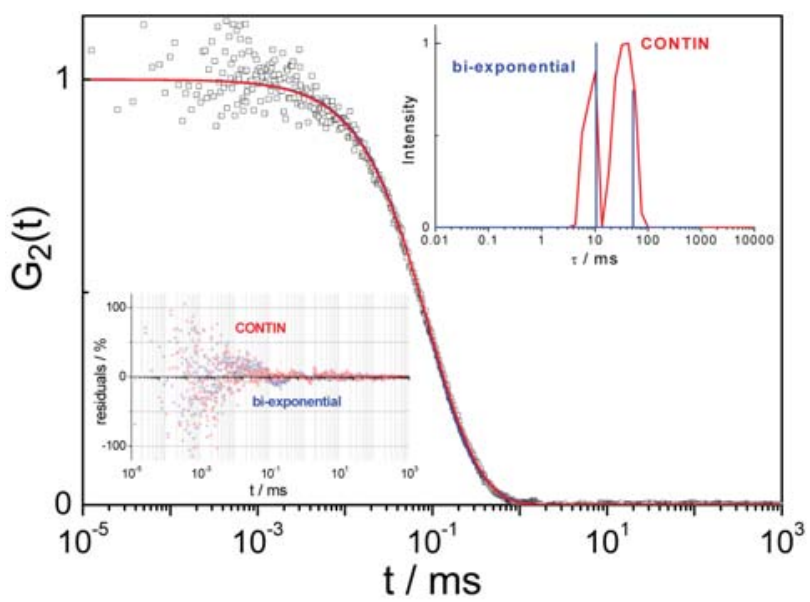

Figure 1. Comparison of the analysis of the correlation function $G_{2}(t)$ made by CONTIN (red) and by the bi-exponential fit (blue) for iPMA with $\alpha_{\mathrm{N}}=0.27$ in $0.05 \mathrm{M} \mathrm{CsCl}$. The open black circles are the experimental data. The upper inset represents the relaxation time distributions of the corresponding $g_{1}(\mathrm{t})$ function and the lower one the residual error. 
For polydisperse samples, equation 4 is written as a weighted average of all possible decays associated with several exponents (multiexponential function). For studied herein particles with moderately broad monomodal and bimodal size distributions, a bi-exponential or a multi-exponential fit to $g_{1}(t)$ was used. The bi-exponential fit was performed with the ORIGIN 8.0 program and was used when two relaxation times of the bimodal distribution were too close to each other and the CONTIN analysis was difficult. This was the case in solutions with $\alpha_{N}>$ 0.27 . The multiexponential fit was based on the original inverse Laplace transform program CONTIN developed by Provencher. ${ }^{23}$ Comparison of both fits is shown in Figure 1 for the case of an iPMA solution with $\alpha_{\mathrm{N}}=0.27$ and $c_{\mathrm{s}}=0.05 \mathrm{M}$ and demonstrates satisfactory agreement between both methods.

\section{Results and Discussion}

\section{1. Scattered Light Intensity in Dependence on $\alpha_{\mathrm{N}}$}

The result of SLS measurements is the intensity of scattered light. According to the Rayleigh equation, ${ }^{18,19}$ intensity is greater when light is scattered from a particle with a higher molar mass, provided that the conformation of the particle and the optical contrast with the medium are the same. Figure 2 shows a plot of the total LS intensity (i.e. the difference $\left(R-R_{\mathrm{o}}\right)_{\theta=0}$ at $\theta=0^{\circ}$, where $R_{\mathrm{o}}$ is the contribution of the solvent to the total LS intensity $R$ ) in dependence on $\alpha_{\mathrm{N}}$ of an iPMA solution in $0.05 \mathrm{M}$

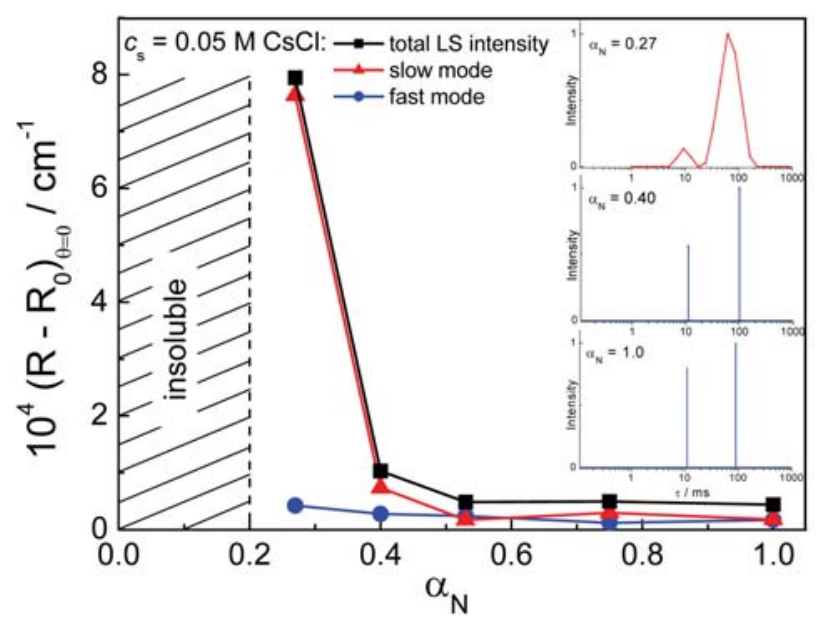

Figure 2. Total LS intensity at $\theta=0^{\circ},\left(R-R_{\mathrm{o}}\right)_{\theta=0}$ (black squares), the contribution of the fast (blue circles) and slow mode (red triangles), and the relaxation time distributions at $\theta=90^{\circ}$ (see insets) for $\mathrm{i}$ PMA in $0.05 \mathrm{M} \mathrm{CsCl}$ at various $\alpha_{\mathrm{N}}$ values. The distribution for $\alpha_{\mathrm{N}}$ $=0.27$ was calculated by the CONTIN program and those for $\alpha_{\mathrm{N}}=$ 0.4 and 1.0 by the bi-exponential fit. The shaded area designates the $\alpha_{\mathrm{N}}$ region where iPMA is insoluble in water.
$\mathrm{CsCl}$. Similar results were obtained for all $c_{\mathrm{s}}$. Clearly, the absolute LS intensity is very high at $\alpha_{\mathrm{N}}=0.27$, falls steeply with increasing $\alpha_{\mathrm{N}}$ and is low and approximately constant for $\alpha_{N} \geq 0.40$. These results suggest that large species - aggregates with high $M_{\mathrm{w}}$ are present in iPMA solution when chains are weakly charged (in the present case this is for $\alpha_{N}$ below approximately 0.3) and that they disappear when $\alpha_{N}$ increases to higher values. Accordingly, the distribution of relaxation times at $\alpha_{\mathrm{N}}=0.27$ (see the upper inset in Figure 2) shows two peaks: (i) the peak at short relaxation times corresponds to small particles (single chains) that diffuse quickly in solution, therefore the term "fast mode" is used for this diffusion, and (ii) the peak at longer relaxation times corresponds to larger particles (aggregates of several chains, i.e. particles with high molar masses) that diffuse slowly. The calculated distributions were used to split the total measured LS intensity into contributions of small (fast mode) and large particles (slow mode), which are plotted in Figure 2 together with the total LS intensity. Details of this procedure can be found in the literature. ${ }^{24-26}$ It can be seen from Figure 2 that the high LS intensity at $\alpha_{\mathrm{N}}=0.27$ comes predominately from the aggregates; the contribution of small particles to the total LS intensity at this $\alpha_{\mathrm{N}}$ is very small.

The calculated relaxation time distributions were bimodal also at higher $\alpha_{\mathrm{N}}$ values (see insets in Figure 2, where this is demonstrated for $\alpha_{N}=0.4$ and 1.0; the distributions in this case were obtained by the bi-exponential fit), with the peak at short times again attributed to single polyion chains ("fast mode") as in the $\alpha_{\mathrm{N}}=0.27$ case. The origin of the peak at longer relaxation times is different as suggested by the low scattering intensity for $\alpha_{\mathrm{N}}>0.27$ and by a significant drop of the contribution of the second peak to $\left(R-R_{\mathrm{o}}\right)_{\theta=0}$. This peak does not represent particles, but is due to so called polyelectrolyte "slow mode" 27,28 originating from electrostatic interactions between highly charged polyions. It is well known $^{2-5,14,17,27,29}$ that this phenomenon leads to low values of the total LS intensity, in contrast to intermolecular association/ aggregation, and to the apparent low diffusion coefficient value measured by DLS. Because the aggregation and the polyelectrolyte slow mode are both associated with a low value of $D$, a generic name "slow mode" is used for both phenomena in Figure 2. The polyelectrolyte slow mode phenomenon will be discussed in more detail in Subsection 3.3.

\section{2. iPMA Aggregates at $\alpha_{\mathrm{v}}=\mathbf{0 . 2 7}$}

Mean peak values of the size distributions, obtained at fixed $q$ were used to estimate the apparent hydrodynamic radius, $R_{\mathrm{h}}$ app, of particles in these solutions and the true $R_{\mathrm{h}}$ was obtained by extrapolating $R_{\mathrm{h}}$ app to $\theta=0$ for each $c_{\mathrm{s}}$. Dependencies of the corresponding relaxation rates on the square of the scattering vector, $q^{2}$, were passing 
through the center of coordinates, confirming the validity of the relationship $\Gamma=1 / \mathrm{l}=D q^{2}$, which applies to a true translational diffusion of colloidal particles in solution. Examples of the $\Gamma$ vs. $q^{2}$ curves are shown Figure $3 \mathrm{a}$ for $c_{\mathrm{s}}$ $=0.07 \mathrm{M} \mathrm{CsCl}$. The slope of these curves is proportional to the diffusion coefficient of particles. The $\Gamma$ vs. $q^{2}$ curve with a high slope corresponds to fast diffusing small particles (individual chains) and is linear. The $\Gamma$ vs. $q^{2}$ curve for the aggregates (large particles, designated as the slow mode in Figure 2) has a considerably lower slope and shows an upward curvature (see inset in Figure 3a) at high $q$ values as a consequence of polydispersity of the aggregates. The hydrodynamic radii of individual chains and of the aggregates, $R_{\mathrm{h}, 1}$ and $R_{\mathrm{h}, 2}$, respectively, are reported in Table 1 and plotted in Figure 4 in dependence on $c_{\mathrm{s}}$. The size of individual polyions is small at all $c_{\mathrm{s}}\left(R_{\mathrm{h}, 1} \approx 9-11\right.$ $\mathrm{nm})$, therefore no angular dependency of the scattered light intensity was observed in this case and data reported in Table 1 are average $R_{\mathrm{h}, 1}$ values measured in the studied $q$ range. In agreement with expectations, the aggregates are considerably larger, up to almost 20-times in comparison with small particles. Their size increases from $R_{\mathrm{h}, 2} \approx$ $80 \mathrm{~nm}$ at $c_{\mathrm{s}}=0.05 \mathrm{M}$ to $R_{\mathrm{h}, 2} \approx 160 \mathrm{~nm}$ at $c_{\mathrm{s}}=0.2 \mathrm{M}$.

Table 1. The size parameters $\left(R_{\mathrm{h}, 1}, R_{\mathrm{h}, 2}, R_{\mathrm{g}, 2}\right)$ and the shape parameter $\rho\left(=R_{\mathrm{g}, 2} / R_{\mathrm{h}, 2}\right)$ in iPMA solutions with $\alpha_{\mathrm{N}}=0.27$ and $c_{\mathrm{p}}=2 \mathrm{gL}^{-1}$ and with various $\mathrm{CsCl}$ concentrations, $c_{\mathrm{s}}$. The uncertainty in $R_{\mathrm{h}}\left(R_{\mathrm{g}}\right)$ values is estimated to be around $10 \%$.

\begin{tabular}{ccccc}
\hline $\boldsymbol{c}_{\mathbf{s}} / \mathbf{m o l ~ L}^{\mathbf{1}}$ & $\boldsymbol{R}_{\boldsymbol{h} \mathbf{1}} \mathbf{~} \mathbf{n m}$ & $\boldsymbol{R}_{\boldsymbol{h , \mathbf { 2 }}} / \mathbf{n m}$ & $\boldsymbol{R}_{\boldsymbol{h} \mathbf{2}} / \mathbf{n m}$ & $\boldsymbol{\rho}$ \\
\hline 0.05 & 10 & 79 & 50 & 0.64 \\
0.07 & 9 & 79 & 48 & 0.61 \\
0.10 & 8 & 88 & 53 & 0.60 \\
0.20 & 11 & 155 & 93 & 0.60 \\
\hline
\end{tabular}

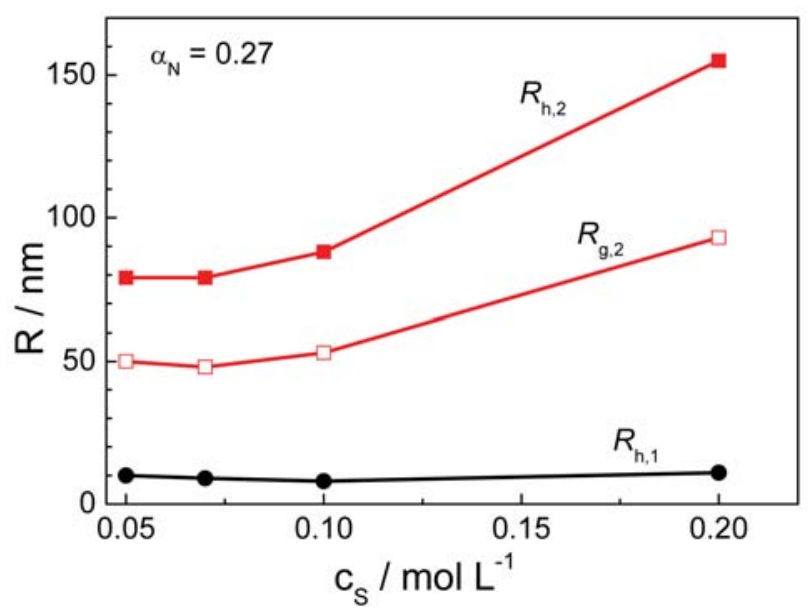

Figure 4. The dependence of $R_{\mathrm{h}, 1}, R_{\mathrm{h}, 2}$, and $R_{\mathrm{g}, 2}$ on $\mathrm{CsCl}$ concentration, $c_{\mathrm{s}}$, in aqueous iPMA solutions with $c_{\mathrm{p}}=2 \mathrm{gL}^{-1}$ and $\alpha_{\mathrm{N}}=0.27$.

In view of the large $R_{\mathrm{h}, 2}$ value, the radius of gyration, $R_{\mathrm{g}, 2}$, could be determined for the aggregates. For this purpose, the second peak in the size distributions was treated separately for the angular dependency of the LS intensity. From $R_{\mathrm{g}, 2}$ and $R_{\mathrm{h}, 2}$, the shape parameter $\rho\left(=R_{\mathrm{g}, 2} / R_{\mathrm{h}, 2}\right)$ was calculated. All these data are reported in Table $1 . R_{\mathrm{g}, 2}$ increases from around $50 \mathrm{~nm}$ at $c_{\mathrm{s}}=0.05$ to around $90 \mathrm{~nm}$ at $c_{\mathrm{s}}=0.2 \mathrm{M}$, whereas values of the shape parameter $\rho$ (= $0.60-0.64)$ show no particular dependence on $c_{\mathrm{s}}$. Note that these $\rho$ values are lower than the value known for a hard sphere $(\rho=0.78)$ and also considerably lower than those for a random coil. ${ }^{18,19}$ They are close to the values reported for microgel-like particles with a core-shell structure, for which $\rho$ was found to be around $0.6 .^{20,30}$

The increase of $R_{\mathrm{g}, 2}$ and $R_{\mathrm{h}, 2}$ with increasing $c_{\mathrm{s}}$ can be explained by proposing that the extent of aggregation

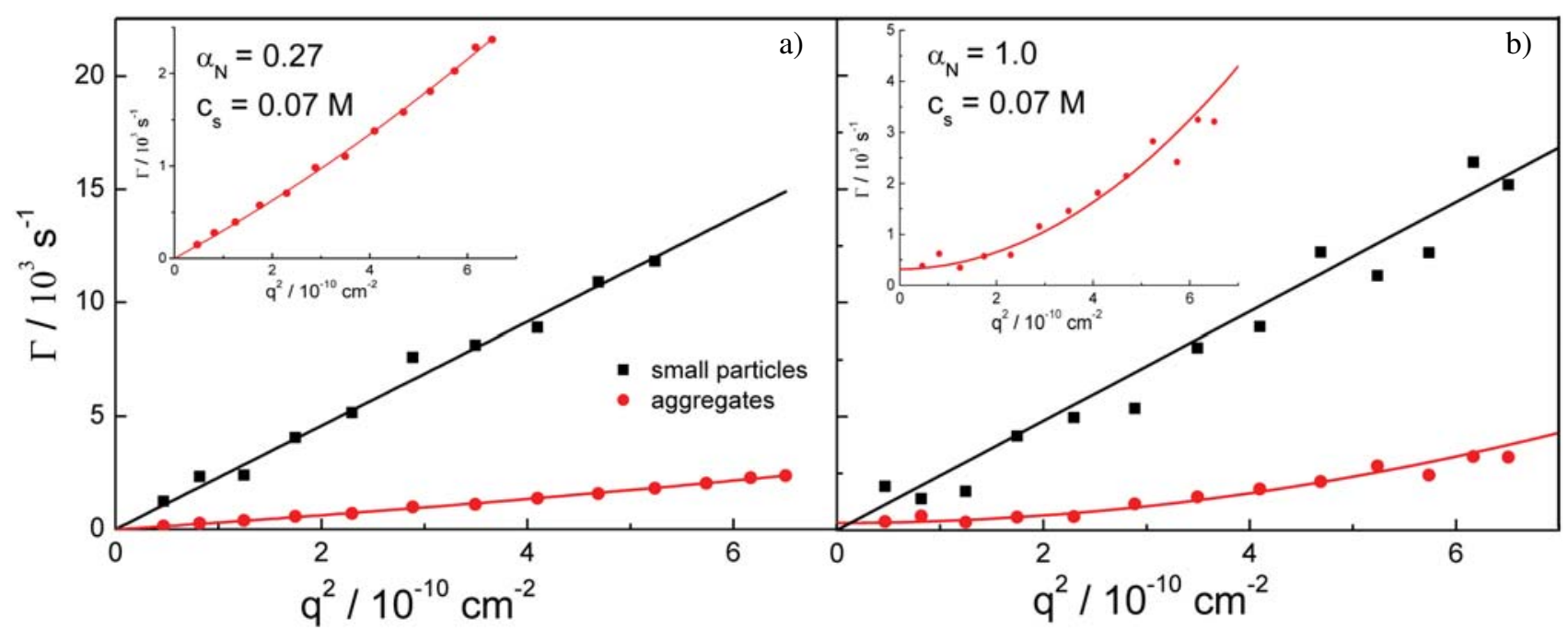

Figure 3. Plots of the relaxation rate, $\Gamma$, versus $q^{2}$ in iPMA solutions with a) $\alpha_{N}=0.27$ in b) $\alpha_{N}=1.0$, both in $0.07 \mathrm{M} \mathrm{CsCl}$. In the insets, the $\Gamma$ vs. $q^{2}$ plot for a) aggregates or b) slow mode is enlarged. 
(association) between iPMA chains increases with increasing salt concentration. This is reasonable because small counterions from the added salt $\left(\mathrm{Cs}^{+}\right)$contribute to screening of electrostatic repulsion between the negatively charged iPMA chains with $\alpha_{N}=0.27$ and thus promote intermolecular association. However, constant $\rho$ values show that, although the aggregates grow, their fractal structure (distribution of mass within the aggregate) is not affected by $\mathrm{c}_{\mathrm{s}}$.

In order to confirm the proposed core-shell structure, we have compared our data with the calculated scattering functions for some typical particle topologies. ${ }^{19}$ The calculated functions and the experimental data for iPMA with $\alpha_{\mathrm{N}}=0.27$ and $c_{\mathrm{s}}=0.07,0.10$, and $0.20 \mathrm{M}$ are presented in the form of a Kratky plot (i.e. the dependence of $(q$ $\left.R_{\mathrm{g}}\right)^{2} P(\mathrm{q})$ on $q R_{\mathrm{g}}$ ) in Figure 5. It can be seen that the majority of the data points remain in the range of low $q$-values $\left(q R_{\mathrm{g}}<1.5\right)$ where the presented topologies are not clearly distinguishable. Only the data obtained for the highest $\mathrm{CsCl}$ concentration $(0.20 \mathrm{M})$ extend up to around $q R_{\mathrm{g}} \approx$ 2.5 , as a consequence of the largest $R_{\mathrm{g}}$ value of the aggregates in $0.20 \mathrm{M} \mathrm{CsCl}$ (see $R_{\mathrm{g}, 2}$ values in Table 1). These data points clearly fit the Debye-Bueche scattering function. Similar results were reported previously ${ }^{16}$ for the same iPMA sample in the presence of $0.1 \mathrm{M} \mathrm{LiCl}, \mathrm{NaCl}$ and $\mathrm{CsCl}$. That study was a comparative investigation of both, iPMA and aPMA. As reported there, $\rho$ of the iPMA aggregates in all $0.1 \mathrm{M}$ alkali chlorides was from $0.58(0.1$ $\mathrm{M} \mathrm{NaCl})$ to $0.67(0.1 \mathrm{M} \mathrm{CsCl})$.

The Debye-Bueche scattering function is reported in the literature for the description of hyperbranched flexible chain molecules and microgel particles from chemically cross-linked flexible chains. ${ }^{20,30}$ Therefore, iPMA aggregates in aqueous $\mathrm{CsCl}$ solutions can be described as sphe-

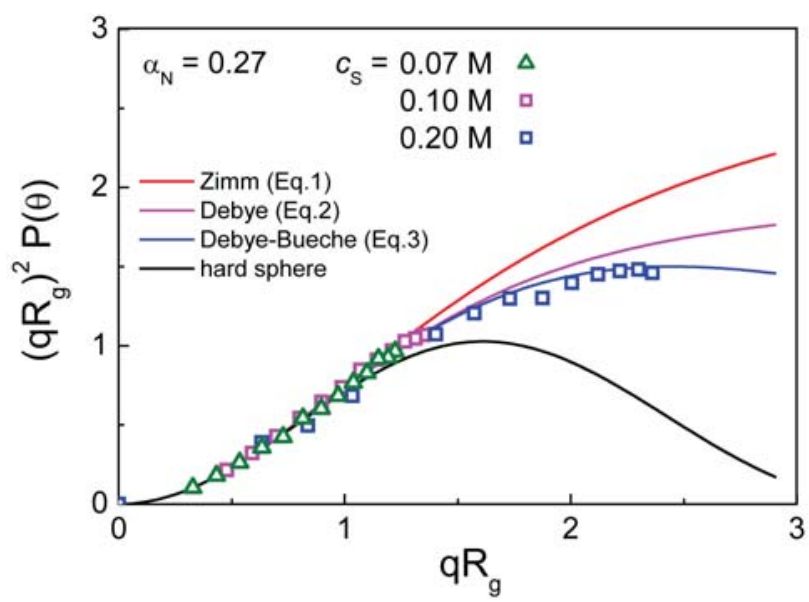

Figure 5. The dependence of $\left(q R_{\mathrm{g}}\right)^{2} P(q)$ on $q R_{\mathrm{g}}$ for four selected particle topologies (calculated according to Equations 1-Zimm, 2Debye, and 3-Debye-Bueche) and the experimental data (points) for large particles (i.e. aggregates) in iPMA solutions with $c_{\mathrm{p}}=2$ $\mathrm{g} / \mathrm{L}$ and $\alpha_{\mathrm{N}}=0.27$ and at three different $\mathrm{CsCl}$ concentrations: $c_{\mathrm{s}}=$ $0.07,0.10$, and $0.20 \mathrm{M}$. rical solvent draining particles with a higher polymer density in the center and a lower one towards the outer surface. On the basis of these results we believe that it is justifiable to approximate the architecture of iPMA aggregates in solutions with added $\mathrm{CsCl}$ with a spherical shape that has a loose corona on its surface and a denser core in the center. Such distribution of mass (with characteristic value of $\rho \approx 0.60$ ) is achieved by very efficient hydrogen bonding between different chains, which is strongly cooperative $\mathrm{e}^{2,3,13,15,16}$ and leads to some kind of segregation of protonated and deprotonated carboxyl groups within the aggregate. The undissociated carboxyl groups are concentrated in the core whereas the dissociated ones constitute the corona, i.e. they are exposed to the solvent and thus provide the solubility of iPMA in water. ${ }^{16}$ It can be imagined that when starting the ionization of carboxyl groups by adding the base $(\mathrm{CsOH})$, the surface carboxyl groups are ionized first. Those in the core remain uncharged and are associated through hydrogen bonding that is reinforced by the favorable presence of hydrophobic methyl groups. ${ }^{27}$ The iPMA aggregate dissolves only at some sufficiently high charge (corresponding to $\alpha_{N}$ larger than $\sim 0.2$ ) when chain repulsion becomes strong enough to disrupt the aggregates. Another result of such association mechanism is also the observed independence of the parameter $\rho$ on salt concentration. The increased salt concentration only facilitates aggregate growth by reducing electrostatic repulsion between charged portions of the chains, but has no effect on attractive interactions, i.e. hydrogen bonding and so called hydrophobic interactions.

\section{3. Slow Diffusion Due to the Polyelectrolyte Effect}

As indicated above, the equation $\Gamma=D q^{2}$ is valid for translational diffusion and predicts that $\Gamma$ vs. $q^{2}$ curves should go through the center of coordinates. For small particles (fast mode), this is the case for all $\alpha_{N}$ as demonstrated in Figure 3 for iPMA with $\alpha_{N}=0.27$ and 1.0 in $0.07 \mathrm{M} \mathrm{CsCl}$. On the other hand, the $\Gamma$ vs. $q^{2}$ curves for the slow mode in iPMA solutions with $\alpha_{N}>0.27$ do not start from the origin of the system of coordinates and therefore do not represent true translational diffusion. ${ }^{27}$ As an example, see the curve for $\alpha_{N}=1$ in the inset of Figure $3 b$ and note that the results were similar for all $\alpha_{\mathrm{N}}>0.27$. The data points for this (slow) mode are considerably more scattered and also more curved in comparison with the data points for the aggregates at $\alpha_{\mathrm{N}}=0.27$ (compare the insets in Figures $3 \mathrm{a}$ and $\mathrm{b}$ ). Sometimes this diffusion process is called anomalous. ${ }^{21}$ The origin of the anomalous diffusion is electrostatic interactions between polyions that result in correlated motion of many charged chains, so called multimacroion or polyion domains. ${ }^{21}$ It was reported that the associated value of the diffusion coefficient of these domains is considerably lower than the diffusion coefficient of individual polyions. ${ }^{19,21,37}$ 
The fast and the slow mode diffusion coefficients, $D_{f}$ and $D_{s}$, respectively, in iPMA solutions with $c_{\mathrm{p}}=2 \mathrm{~g} / \mathrm{L}$ are plotted in Figure 6 as a function of $\alpha_{\mathrm{N}}$ for all $c_{\mathrm{s}}$. In agreement with the above statement, the value of $D_{s}$ is around one order of magnitude lower than $D_{f}$ Moreover, $D_{f}$ and $D_{s}$ are almost independent of $c_{\mathrm{s}}$ and $\alpha_{\mathrm{N}}$ at the studied polymer concentration. The correlation lengths associated with the $D$ values in Figure 6 are in the range of 7-14 nm (= $R_{\mathrm{h}, 1}$ ), obtained from $D_{f}$, and $40-110 \mathrm{~nm}$, obtained from $D_{s}$. The independence of $D_{f}$ and $D_{s}$ on $\alpha_{\mathrm{N}}$ was recently demonstrated for both iPMA and aPMA in different alkali chloride solutions, but only for a single salt concentration $c_{\mathrm{s}}=0.10 \mathrm{M}$.

Other authors have previously ${ }^{28}$ determined diffusion coefficients in salt free solutions of so called conventional, i.e. atactic, PMA with a similar $M_{\mathrm{w}}(=30.000$ $\mathrm{g} / \mathrm{mol}$ ) as in the case of iPMA in this study, but with a considerably larger polymer concentration $\left(c_{\mathrm{p}}=36.6 \mathrm{~g} / \mathrm{L}\right)$. It was demonstrated that in the $\alpha_{\mathrm{N}}$ range $0-0.4, D_{f}$ of aPMA chains increases and $D_{s}$ decreases with increasing $\alpha_{\mathrm{N}}$, whereas for $\alpha_{N} \geq 0.4$ they are both nearly independent of $\alpha_{\mathrm{N}}$. Taking into account that our measurements apply to the stereoregular iPMA with a non-zero degree of neutralization $\left(\alpha_{N}>0.27\right)$ and to solutions with a non-negligible amount of added $\mathrm{CsCl}\left(c_{\mathrm{s}} \geq 0.05 \mathrm{M}\right.$; compare this with salt-free conditions for aPMA in ref. 28), we conclude that these results are in a reasonable agreement with each other.

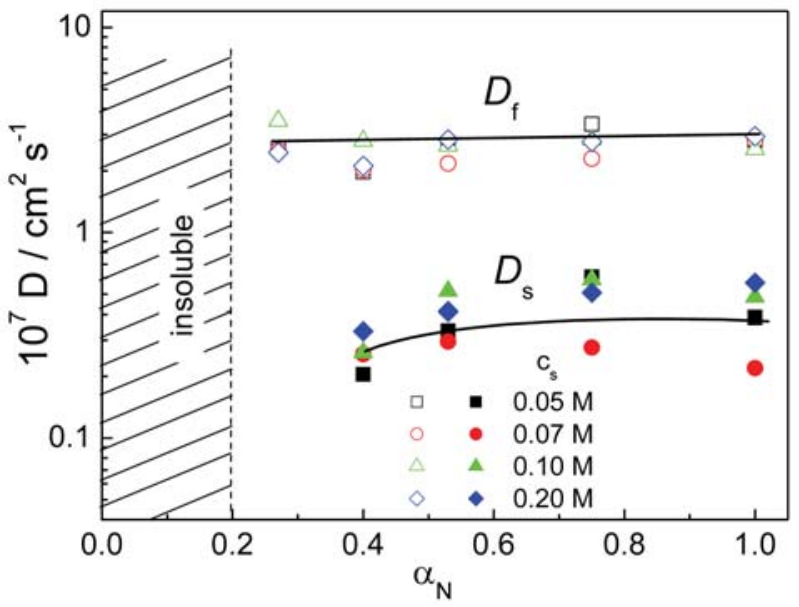

Figure 6. Dependence of the fast, $D_{\mathrm{f}}$, and slow diffusion coefficient, $D_{\mathrm{s}}$, on degree of neutralization, $\alpha_{\mathrm{N}}$, in aqueous iPMA solutions with $c_{\mathrm{p}}=2 \mathrm{~g} / \mathrm{L}$ and at various $\mathrm{CsCl}$ concentrations, $c_{\mathrm{s}}(=$ $0.05-0.20 \mathrm{M})$. The shaded area designates the $\alpha_{\mathrm{N}}$ region where iPMA is insoluble in water.

It is normally expected that the slow mode phenomenon disappears when the amount added low molar mass salt is sufficient to completely screen electrostatic repulsion between the polyions. Förster et al ${ }^{38}$ reported diffusion coefficients of quaternized poly(2-vinyl pyridi- ne), QPVP, in aqueous solutions over a broad range of the polyion concentration (in moles of charged groups, $c_{p}^{c h}$ ) to the added salt concentration, denoted as $\lambda\left(=c_{p}^{c h} / c_{s}\right)$. They demonstrated that the slow diffusive process is always observed in polyelectrolyte solutions for $\lambda$ larger than 1, i.e. when polyion charges are in excess with respect to the salt charges and electrostatic repulsions between polyions are not effectively screened. Solution conditions with $\lambda \approx 1$ (equal amount of charges from the polyelectrolyte and from the slat) are described as the transition regime, where the slow mode gradually appears (or disappears) and for $\lambda<1$ (low polyion or high salt concentration) only the fast diffusion process of single chains is observed. In the case of QPVP in the presence of monovalent counterions, the slow mode disappeared for $\lambda$ values below $\sim 1-5{ }^{38}$

With iPMA solutions investigated herein, the studied $\lambda$ range is somewhat below 1 (from $\lambda \approx 0.03$ at $\alpha_{\mathrm{N}}=$ 0.27 and $c_{\mathrm{s}}=0.20 \mathrm{M}$ to $\lambda \approx 0.465$ at $\alpha_{\mathrm{N}}=1.0$ and $c_{\mathrm{s}}=0.05$ $\mathrm{M})$, which means that the number of charges from small counterions exceeds the one originating from the polyion (i.e. salt is in small excess). However, as distinguished from the QPVP case, the slow mode is still observed. This can be explained by proposing that electrostatic interactions between the iPMA polyions, as compared to the QPVP ones, are stronger. This may be a consequence of different chain rigidity and distribution of charges on iPMA that would lead to higher polyion charge density. The data in Figure 6 suggest that in the iPMA case even $0.20 \mathrm{M} \mathrm{CsCl}$ is not sufficient to completely screen strong electrostatic forces. Further investigations are necessary to explain these findings in more detail.

\section{Conclusions}

We have studied dynamic behavior of isotactic polymethacrylic acid, iPMA, chains in aqueous solutions with added $\mathrm{CsCl}$ at various concentrations, $c_{\mathrm{s}}$, in dependence on degree of neutralization of polyion's carboxyl groups, $\alpha_{\mathrm{N}}$, by simultaneously performing static, SLS, and dynamic light scattering, DLS, measurements. All correlation functions measured by DLS were bimodal and revealed two diffusion modes. The fast diffusion mode was associated with individual iPMA chains whereas the slow diffusion mode either represents aggregates of several chains (the case with $\alpha_{\mathrm{N}}=0.27$ ) or so called polyion domains (higher polyion charges, $\alpha_{\mathrm{N}}>0.27$ ). The hydrodynamic radius of individual chains, $R_{\mathrm{h}, 1}$, was in the range $8-11$ $\mathrm{nm}$, but no dependence of $R_{\mathrm{h}, 1}$ on either $\alpha_{\mathrm{N}}$ or $c_{\mathrm{s}}$ could be deduced. The hydrodynamic radius of the aggregates, $R_{\mathrm{h}, 2}$, at $\alpha_{\mathrm{N}}=0.27$ was found to increase with increasing $c_{\mathrm{s}}$ from $R_{\mathrm{h}, 2} \approx 80 \mathrm{~nm}$ at $c_{\mathrm{s}}=0.05 \mathrm{M}$ to $R_{\mathrm{h}, 2} \approx 160 \mathrm{~nm}$ at $c_{\mathrm{s}}=0.20 \mathrm{M}$, whereas the shape parameter, $\rho$, was found to be independent of $c_{\mathrm{s}}$. This means that the aggregates grow with increasing $c_{\mathrm{s}}$, but their nature (distribution of mass within the aggregate) remains the same. The increase in size at 
higher $c_{\mathrm{s}}$ is expected because the counterions from the added salt $\left(\mathrm{Cs}^{+}\right)$contribute to screening of electrostatic repulsion between iPMA chains with a relatively low charge (corresponding to $\alpha_{\mathrm{N}}=0.27$ ). As suggested by the value of $\rho(=0.60-0.64)$, the aggregates have characteristics of microgel particles with a core-shell structure. Consequently, the scattering functions for the aggregates fitted the Debye-Bueche function.

In samples with $\alpha_{N}>0.27$, the polyelectrolyte slow mode was detected, which is due to repulsive interactions between negatively charged polyion chains and manifests itself as a correlated motion of chains. Light scattering measurements detect such motion as an additional diffusive mode, often ascribed to loose multimacroion (or polyion) domain formation. It has to be stressed that these polyion domains are not real particles but regions of correlated motion of polyions that are detected by DLS. The value of the diffusion coefficient of such domains can be determined from the measured correlation functions. We have determined the diffusion coefficients of individual polyions (the fast diffusion coefficient, $D_{\mathrm{f}}$ ) and of such polyion domains (the slow diffusion coefficient, $D_{\mathrm{s}}$ ) in dependence on $\alpha_{\mathrm{N}}$ and $c_{\mathrm{s}}$. The results show that both $D_{\mathrm{f}}$ and $D_{\mathrm{s}}$ are nearly independent of $\alpha_{\mathrm{N}}$ and $c_{\mathrm{s}}$ at the studied polymer concentration.

\section{Acknowledgment}

This work was financially supported by the Slovenian Research Agency, ARRS, through the Physical Chemistry program P1-0201.

\section{References}

1. V. V. Khutoryanskiy, Int. J. Pharm. 2007, 334, 15-26. http://dx.doi.org/10.1016/j.ijpharm.2007.01.037

2. K. Kogej, H. Berghmans, H. Reynaers, S. Paoletti, J. Phys. Chem. B. 2004, 108, 18164-18173.

http://dx.doi.org/10.1021/jp048657k

3. B. Jerman, M. Breznik, K. Kogej, S. Paoletti, J. Phys. Chem. B. 2007, 111, 8435-8443. http://dx.doi.org/10.1021/jp0676080

4. J. Eliassaf, A. Silberberg, A. Katchalsky, Nature. 1955, 176, 1119-1119. http://dx.doi.org/10.1038/1761119a0

5. N. Vlachy, J. Dolenc, B. Jerman, K. Kogej, J. Phys. Chem. B. 2006, 110, 9061-9071. http://dx.doi.org/10.1021/jp060422g

6. G. R. Desiraju, in J. L. Atwood, J. W. Steed (Eds.): Encyclopedia of Supramolecular Chemistry, Marcel Dekker Inc: New York, USA, 2004, pp. 658-665.

7. E.M. Loebl, J.J. O'Neill, J. Polym. Sci. 1960, 45, 538-540. http://dx.doi.org/10.1002/pol.1960.1204514629

8. V. Crescenzi, Adv. Polym. Sci. 1968, 5, 358-386. http://dx.doi.org/10.1007/BFb0050986
9. M. Nagasawa, T. Murase, K. Kondo, J. Phys. Chem. 1965, 69, 4005-4012. http://dx.doi.org/10.1021/j100895a060

10. J.C. Leyte, H.M.R. Arbouw-van der Veen, L.H. Zuiderweg, J. Phys. Chem. 1972, 76, 2559-2561. http://dx.doi.org/10.1021/j100662a014

11. J.C. Leyte, M. Mandel, J. Polym. Sci., Part A: Gen. Pap. 1964, 2, 1879-1891. http://dx.doi.org/10.1002/pol.1964.100020429

12. Y. Muroga, I. Nada, M. Nagasawa, Macromolecules. 1985, 18, 1580-1582. http://dx.doi.org/10.1021/ma00150a010

13. E. van den Bosch, G. Filipcsei, H. Berghmans, H. Reynaers, Macromolecules. 2004, 37, 9673-9675. http://dx.doi.org/10.1021/ma047821z

14. B. Jerman, K. Kogej, Acta Chim. Slov. 2006, 53, 264-273.

15. S. Sitar, V. Aseyev, K. Kogej, Polymer. 2014, 55, 848-854. http://dx.doi.org/10.1016/j.polymer.2014.01.007

16. S. Sitar, V. Aseyev, K. Kogej, Soft Matter. 2014, 10, 77127722. http://dx.doi.org/10.1039/C4SM01448K

17. S. Ohoya, S. Hashiya, K. Tsubakiyama, T. Matsuo, Polym. J. 2000, 32, 133-139. http://dx.doi.org/10.1295/polymj.32.133

18. W. Schärtl: Light Scattering from Polymer Solutions and Nanoparticle Dispersions. Springer-Verlag Berlin, Heidelberg, 2007.

19. W. Brown, (Ed): Dynamic light scattering: the method and some applications. Clarendon Press, Oxford, 1993.

20. W. Burchard, Macromolecules. 2004, 37, 3841-3849. http://dx.doi.org/10.1021/ma0499501

21. M. Sedlák, Langmuir. 1999, 15, 4045-4051. http://dx.doi.org/10.1021/la981189j

22. P. Kratochvíl, in M.B. Huglin Editor: Light Scattering from Polymer Solutions, Academic Press: London, 1972, pp. 333384.

23. S. Provencher, Inverse Problems home page, http://sprovencher.com/index.shtml (accessed: 26 Jan, 2011).

24. R. Klucker, J.P. Munch, F. Schosseler, Macromolecules. 1997, 30, 3839-3848. http://dx.doi.org/10.1021/ma9617101

25. E. Raspaud, D. Lairez, M. Adam, J.-P. Carton, Macromolecules. 1994, 27, 2956-2964. http://dx.doi.org/10.1021/ma00089a011

26. E. Tarassova, V. Aseyev, A. Filippov, H. Tenhu, Polymer. 2007, 48, 4503-4510. http://dx.doi.org/10.1016/j.polymer.2007.05.069

27. R. Cong, E. Temyanko, P. S. Russo, N. Edwin, R. M. Uppu, Macromolecules. 2005, 39, 731-739. http://dx.doi.org/10.1021/ma051171x

28. M. Sedlák, Č. Kon̆ákt, P. Štěpánek, J. Jakeš, Polymer. 1987, 28, 873-880. http://dx.doi.org/10.1016/0032-3861(87)90156-X

29. J. Eliassaf, A. Silberberg, Polymer. 1962, 3, 555-564. http://dx.doi.org/10.1016/0032-3861(62)90103-9

30. G. Savin, W. Burchard, Macromolecules. 2004, 37, 30053017. http://dx.doi.org/10.1021/ma0353639

31. S. Förster, M. Schmidt, M. Antonietti, Polymer. 1990, 31, 781-792.

http://dx.doi.org/10.1016/0032-3861(90)90036-X 


\section{Povzetek}

S hkratnimi meritvami statičnega, SLS, in dinamičnega sipanja svetlobe, DLS, smo študirali dinamično obnašanje verig izotaktične polimetakrilne kisline, iPMA, v vodnih raztopinah z dodatkom $\mathrm{CsCl} v$ različnih koncentracijah, $c_{\mathrm{s}}$, v odvisnosti od stopnje nevtralizacije, $\alpha_{\mathrm{N}}$, karboksilnih skupin skupin na poliionu. Vse izmerjene korelacijske funkcije z DLS so bile bimodalne in so pokazale na prisotnost dveh difuzijskih načinov (modusov). Hitri difuzijski način smo povezali $\mathrm{z}$ individualnimi verigami iPMA in počasnega $\mathrm{z}$ agregati med verigami (primer $\alpha_{\mathrm{N}}=0.27$ ) ali pa s tvorbo tako imenovanih poliionskih domen (večji naboji na poliionu, $\alpha_{\mathrm{N}}>0.27$ ). Hidrodinamski radij individualnih verig, $R_{\mathrm{h}, 1}$, je bil 7-14 $\mathrm{nm}$, vendar pa nismo opazili nobene posebne odvisnosti $R_{\mathrm{h}, 1}$ od $\alpha_{\mathrm{N}}$ ali $c_{\mathrm{s}}$. Hidrodinamski radij agregatov, $R_{\mathrm{h}, 2}$, je naraščal od $R_{\mathrm{h}, 2} \approx 80 \mathrm{~nm}$ pri $c_{\mathrm{s}}=0.05 \mathrm{M}$ do $R_{\mathrm{h}, 2} \approx 160 \mathrm{~nm}$ pri $c_{\mathrm{s}}=0.20 \mathrm{M}$, medtem ko je bil faktor oblike, $\rho$, neodvisen od $c_{\mathrm{s}}$. Na osnovi tega smo sklepali, da velikost agregatov sicer narašča s $c_{\mathrm{s}}$, vendar pa njihova oblika (porazdelitev mase) ostaja nespremenjena. Večja velikost pri večji $c_{\mathrm{s}}$ je pričakovana, saj protiioni iz dodane soli $\left(\mathrm{Cs}^{+}\right)$prispevajo k senčenju elektrostatskega odboja med verigami iPMA z $\alpha_{N}=0.27$. Vrednosti parametra oblike $(\rho=0.61-0.67)$ kažejo, da imajo agregati značilnosti mikrogelov s tako imenovano »core-shell« strukturo. Sipalne krivulje za agregate so se ujemale z Debye-Buechejevo funkcijo.

$\mathrm{V}$ vzorcih $\mathrm{z} \alpha_{\mathrm{N}}>0.27$ smo zasledili tako imenovane poliionske domene, ki so posledica elektrostatskega odboja med negativno nabitimi verigami poliiona. Meritve sipanja svetlobe tako gibanje zaznajo kot dodaten difuzijski način, ki ga pogosto pripisujejo koreliranemu gibanju večih verig. Te domene niso realni delci, ampak strukture $\mathrm{v}$ raztopini $\mathrm{z}$ dovolj dolgim življenjskim časom, da jih lahko zaznamo z DLS meritvami in določimo vrednost difuzijskega koeficienta takih domen iz izmerjenih korelacijskih funkcij. Določili smo difuzijske koeficiente za individualne verige poliionov (to smo imenovali hitra difuzija in difuzijski koeficient označili z $D_{\mathrm{f}}$ ) in za poliionske domene (ta difuzijski način smo imenovali počasna difuzija in difuzijski koeficient označili z $D_{\mathrm{s}}$ ) v odvisnosti od $\alpha_{\mathrm{N}}$ in $c_{\mathrm{s}}$. Rezultati so pokazali, da sta tako $D_{\mathrm{f}}$ kot $D_{\mathrm{s}}$ skoraj neodvisna od $\alpha_{\mathrm{N}}$ in $c_{\mathrm{s}}$ za preiskovano koncentracijo iPMA. 